\title{
Synthesizing Nano Silica Nanoparticles from Barley Grain Waste: Effect of Temperature on Mechanical Properties
}

\author{
Evidence Akhayere $^{1,3}$, Doga Kavaz ${ }^{2,3 *}$, Ashok Vaseashta ${ }^{4}$ \\ ${ }^{1}$ Cyprus International University, Department of Environmental Science, Nicosia, Turkey \\ ${ }^{2}$ Cyprus International University, Department of Bioengineering, Nicosia, Turkey \\ ${ }^{3}$ Environmental Research Centre, Cyprus International University, Nicosia, Turkey \\ ${ }^{4}$ International Clean Water Institute, Manassas, Virginia and New Jersey City University \\ - State University of New Jersey, Jersey City, New Jersey, USA
}

Received: 26 February 2018

Accepted: 15 May 2018

\begin{abstract}
In this investigation we report the synthesis of nano silica (NS) nanoparticles from barley grass waste - an environmental burden - using varying temperatures during preparation. The temperatures used during the investigation were $400,500,600$, and $700^{\circ} \mathrm{C}$, and we studied its effects on the mechanical properties of the NS nanoparticles for use in environmentally friendly applications. Furthermore, the NS nanoparticles resulting from high temperature synthesis were characterized using various characterization methodologies such as X-ray diffraction (XRD), scanning electron microscopy (SEM), energy-dispersive X-ray (EDX) analysis, Brunauer-Emmett-Teller (BET), Fourier transform infrared (FTIR) and X-ray fluorescence (XRF) spectrometry analysis. The result of the various characterizations revealed the presence of elemental $\mathrm{Si}, \mathrm{C}$, and $\mathrm{O}$ in the synthesized nanoparticles. Using $\mathrm{XRF}$, we observed that higher amounts of $\mathrm{SiO}_{2}$ particles from NS were obtained at $600^{\circ} \mathrm{C}$ and $700^{\circ} \mathrm{C}$, also resulting in higher strength in the mechanical properties. Furthermore, using the Brunauer-Emmett-Teller (BET) methodology, we were able to measure the surface area corresponding to $150 \mathrm{~m}^{2} / \mathrm{g}$. Additional methodologies were used, such as differential scanning calorimetric (DSC), thermo gravimetric analysis (TGA), SEM, and tensile analysis. The results of this study showed improved and stable mechanical properties with the increase in temperature during synthesis.
\end{abstract}

Keywords: barley, agricultural waste, nanosilica, nanoparticles, mechanical properties

*e-mail: dkavaz@ciu.edu.tr 


\section{Introduction}

Current global municipal solid waste (MSW) generation levels are approximately 1.3 billion tons per year and are expected to increase to approximately 2.2 billion tons per year by 2025 . Waste production arising from different industries and other means is a growing concern, as they reach their near capacity [1]. Various resource conservation mechanisms such as recycling and composting prevent hundreds of millions of tons of materials being disposed, preventing the release of carbon dioxide in the atmosphere. Although addressing the entire problem is beyond the scope of this publication, we intend to address one of the aspects: the resource conservation of rice husk ash (RHA).

The brewing industry employs a variety of raw materials for its beer production, ranging from barley grain (the major ingredient) [2] to hops and yeast. Apparently, it is worth noting that the raw material (barley grain) produces a very high amount of barley grain waste, posing a major environmental concern. As noted by Van Donkelaar et al. [3], this waste byproduct contributes to $60 \%$ biochemical oxygen demand (BOD) as well as suspended solids. Many methods have been employed by industrialists and agriculturalists to dispose of this waste, one of which is the conventional landfilling process. Fresh brewer's grains left on the ground outside a brewery spoil quickly and can become environmental pollution, including contributing to water pollution. To maintain an ecological balance and to sustainably utilize this waste product, it is important to convert it into useful materials, thereby shifting from an older, cost-ineffective paradigm of conventional landfilling to transforming the waste into something useful, including but not limited to use as animal feed to alleviate the environmental impact of the brewing process. A paradigm-shift to an ecologically friendly (green) byproduct using inexpensive and sustainable sources is a highly recommended form of resource conservation [4]. Similarly, if other waste resulting from wood processing, such as sawdust and ash, rubber crump, plastic waste (such as plastic bags and singleuse water bottles), coconut husk and shell, textile waste (sludge and fiber), etc. were to be considered for resource conservation, it would lead to lessening the waste disposal crisis to a large extent [5-7].

The field of nanotechnology has proven to be very active and vital, and it spans areas of research across many fields, including electronics, aviation, defense, medicine, and dental studies [8,9]. Numerous technological advances have arisen from the potential of nanoscale materials to exhibit unique properties that are attributable to their small size. Furthermore, advances in material synthesis, device fabrication, and characterization have provided the means to study, understand, control, or even employ the transitional characteristics between isolated atoms and molecules, and bulk materials. The field involves the design, synthesis, characterization, and application of materials that have been synthesized in nanometer scale [10-12]. It is very important to note that at the nanoscale, the biological, chemical, and physical properties of materials are different from those of individual elements in macro and micro scales, thus enabling large opportunities in the development of new classes of highly advanced materials that have the potential to address and solve several unique problems and challenges that demand high-tech applications. Furthermore, many nanoparticles (NPs), viz. of noble metals, semiconductors, magnetic materials, and their composites have also paved the way for swift advancement in biomedical applications, such as drug carriers, gene delivery, and tissue engineering $[13,14]$

Silicon (Si) is the second most abundant element on earth - after oxygen. It occurs in nature, sand, soil, and through chemical and biological means. Silicon is usually available in crystalline, polycrystalline, or amorphous states as silicon dioxide (silica, $\mathrm{SiO}_{2}$ ) $[15$, 16]. Plants take up silicon from soil water in the form of water-soluble silicic acid. Silica can be seen to play an important physiological role in the growth of plants as a removal agent of biotic and abiotic stress. One interesting fact about silica-based NPs is that they provide a driving mechanism for biomedical applications, and it is further interesting to note that silicon is biocompatible and bioactive [17]. According to Shariff et al. [18], barley is a major waste product of agriculture and has been known to possess a high silica content, making it a good raw material from which silicon-related substances can be produced, which includes silica, silicon tetrachloride, pure silicon, zeolite, and many other silicon-based byproducts. Many processes can be used for preparing silica nano particles, including microwave hydrothermal processes [19], sol-gel processes [20], and combustion synthesis [21]. Most methods used to produce silica on a large scale involve the use of very high temperature processes (in proximity of $1300^{\circ} \mathrm{C}$ ), which are not only energyintensive but also may be hazardous to the environment due to large volumes of $\mathrm{CO}_{2}$ gas production [22]. In general, it can be stated that a vast majority of methods that produce silica are energy- and time-intensive, produce low-purity silica, and are inefficient, thus requiring low energy consumption, low $\mathrm{CO}_{2}$ generation, and a sustainable method of silica production - which cannot be overemphasized.

As agricultural activities are increasing, the generation of waste is growing exponentially. As awareness of ways to handle and process such wastes in increasing vis-à-vis use of nanomaterials, we describe an easy and cost-effective solution to transforming barley grass agricultural waste into a more useful material known as nano silica, which has an increased economic demand employing principles of green chemistry and sustainable methodology. Furthermore, we demonstrate its mechanical properties, and the effects of temperature on the nature of the nano material to show their applicability with many nano-composites 

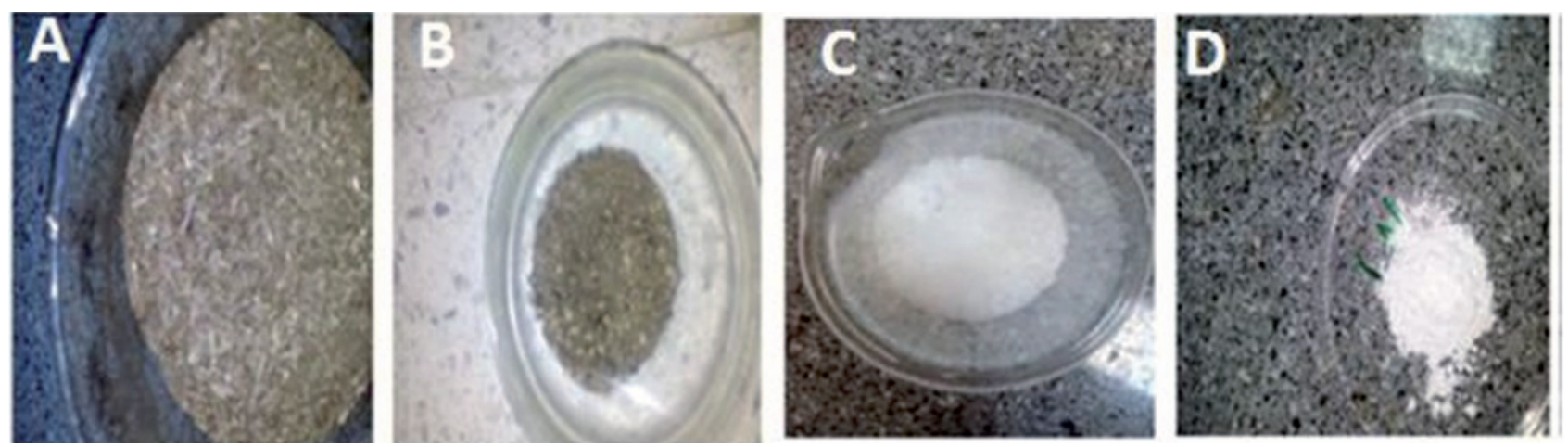

Fig. 1. Synthesis digital image from harvested barley to nanosilica: a) barley, b) barley after blending and washing, c) acid-treated barley ash, and d) acid-treated barley followed by combustion.

that can be used for lightweight and mechanically strong applications. Overall, we demonstrate in this report a low-cost method for the synthesis of very high-quality nano silica nanoparticles for mechanical applications while mitigating environmental waste. Fig. 1 shows harvested barley to nanosilica nanoparticles during various processing stages.

\section{Material and Methods}

\section{Materials}

The barley used in the synthesis of nano silica was collected from Haspolat, Lefkoşa farms, after which it was dried and stored at $100^{\circ} \mathrm{C}$. Other chemicals that were used for barley treatment include distilled water, $2 \mathrm{M} \mathrm{HCl}$, and $10 \% \mathrm{w} / \mathrm{v} \mathrm{HNO}_{3}$ - all of which were of analytical grade.

\section{Synthesizing Silica Nanoparticles from Barley Grass}

The barley sample was washed with distilled water and dried at $100^{\circ} \mathrm{C}$ for 24 hrs., after which it was powdered into fine particles using a miller. This powdered barley was then boiled in $10 \% \mathrm{w} / \mathrm{v} \mathrm{HNO}_{3}$, rinsed with distilled water, and left to dry for $24 \mathrm{hrs}$. at $60^{\circ} \mathrm{C}$. The resulting sample was then refluxed with $2 \mathrm{M} \mathrm{HCl}$ for 6 hours, after which the sample was apportioned into four and heated in a furnace at 400 , $500,600,700^{\circ} \mathrm{C}$, respectively. The four samples were further analyzed.

\section{Characterizing the Silica Aanoparticles}

\section{$X$-ray Diffraction (XRD)}

The XRD analysis carried out on the synthesized nano silica sample prepared at $500^{\circ}, 600^{\circ}$, and $700^{\circ} \mathrm{C}$ was performed with the use of a Rigaku DMAX 2100 diffractometer with monochromatic $\mathrm{CuK} \alpha$ radiation $(\gamma=0.154056 \mathrm{~nm})$ at $40 \mathrm{kV}$. The XRD data for the analysis of barley grass was collected from 10 to $80^{\circ}$ of $2 \theta$ at a scan rate of $2^{\circ} 2 \theta$ per minute.

\section{Fourier Transformed Infrared (FTIR)}

The silica powder obtained from barley was characterized in a Shimadzu IR prestige-21 spectrometer. The IR spectra was recorded at $2 \mathrm{~cm}$ for barley with the unprocessed barley powder used as reference point. The IR was analyzed for barley and a graph was plotted for showing major chemical groups showing the emergence of silica.

\section{Brunauer-Emmett-Teller (BET) Surface Area Analyzer}

The surface area of Silica Nano particles was acquired utilizing the BET strategy at liquid nitrogen temperature. The first process was to degas the sample under vacuum at $200^{\circ} \mathrm{C}$ for $1 \mathrm{~h}$. After out-gassing, the sample was then placed in helium gas to cool, after which the weight of the dry and out-gassed sampled was measured.

\section{Differential Scanning Calorimetry (DSC)}

This study made use of the differential scanning calorimeter (DSC) to observe the heat required for temperature increase as well as the thermal properties of the synthesized nano silica. $15 \mathrm{mg}$ of the synthesized samples was placed into an aluminum pan that was then closed tightly, while the analysis was carried out with the help an empty reference pan. The sample was then cooled to $-40^{\circ} \mathrm{C}$ and then heated from to $250^{\circ} \mathrm{C}$ at $5^{\circ} \mathrm{C} / \mathrm{min}$ and held at constant temperature for $2.0 \mathrm{~min}$ (this was done in order to annul the previous thermal history of the sample). The samples were then cooled from $200^{\circ} \mathrm{C}$ to $-40^{\circ} \mathrm{C}$ at $20.0^{\circ} \mathrm{C} / \mathrm{min}$, after which the samples were again heated from $-40^{\circ} \mathrm{C}$ to $250^{\circ} \mathrm{C}$ at $5.0^{\circ} \mathrm{C} / \mathrm{min}$. 


\section{Thermogravimetric Analysis (TGA)}

Thermogravimetric analysis (TGA) was carried out in the nitrogen atmosphere. This was done by heating $15 \mathrm{mg}$ of synthesized nano silica samples in platinum pans at $30^{\circ} \mathrm{C}$ to $750^{\circ} \mathrm{C}$ in a $50 \mathrm{~mL}$ flow of $\mathrm{N}_{2}$. It also employed the use of heat, at $5^{\circ} \mathrm{C} / \mathrm{min}$, with continuous monitoring and recording of sample temperature, sample mass, the first derivative, and heat flows.

\section{Tensile Test}

Tensile properties were carried out using a system known as mechanical testing. The nano silica samples were dried separately in a vacuum oven at $60^{\circ} \mathrm{C}$ for $1 \mathrm{~h}$ and then kept in a desiccator until it was tested.

\section{Scanning Electron Microscopy (SEM)}

The scanning electron microscopy characterization of synthesized nano silica from barley was done with the use of SEM microscopy (JEOL JEM-6610LV) in order to study particle sizes, aggregations, morphology, and shapes.

\section{Results and Discussion}

This study was conducted in order to develop an alternative to using landfills and obsolete means of waste disposal methods to dispose of barley grass processing waste and other types of industrial and farming waste into a sustainable and important material known as nanosilica. In fact, barley-based biomass contains organic (cellulose, hemicellulose, and lignin) and inorganic substances $\left(\mathrm{SiO}_{2}, \mathrm{Na}, \mathrm{Ca}, \mathrm{Mg}, \mathrm{Fe}, \mathrm{K}\right.$, $\mathrm{Mn}$, and $\mathrm{Al}$ ) [17], and ongoing research intends to find additional applications. In North Cyprus and most other agriculturally intensive countries, there is a high rate of generation of barley waste and research that has the potential to convert a large environmental problem into environmentally friendly materials and products. As the application of silica nanoparticles (SNPs) is ever increasing in various industrial products, the production of silica from waste products becomes a very attractive option [23]. However, there is a need to reduce or possibly remove metal ion impurities present in barley grass. To optimize the extraction of silica and in turn improve the purity of high-quality SNPs from barley grass as agricultural waste by environmentally friendly techniques [24] is the overall goal of this investigation.

The characterization was carried out on the synthesized nanosilica, and showed that the method with which the nanosilica was synthesized (acid treatment and heat treatment) produced high amounts of silica. Characteristics of nanomaterials are usually size dependent and exhibit special physical and chemical properties as compared to the bulk of the material [12, 25]. We observe that nanosized powders had lower temperature effects with respect to the conventional micro-sized powders, and this is attributed to their high contact surface area as opposed to that with standard particles. Ghorbani et al. [16] observed that the optimization temperature for silica extraction from the various plants were kept at $600^{\circ} \mathrm{C}$ and $700^{\circ} \mathrm{C}$. We, however, optimized at four different temperatures - $400^{\circ} \mathrm{C}, 500^{\circ} \mathrm{C}, 600^{\circ} \mathrm{C}$, and $700^{\circ} \mathrm{C}$ to compare the effects of the temperature changes on the characteristics and integrity of the synthesized silica [26].

It was important in our study to characterize the synthesized barley to understand the nature of the synthesized nanomaterial at different temperatures. It has been reported by previous studies that treatment of waste and biomass with $\mathrm{HCl}, \mathrm{HNO}_{3}, \mathrm{H}_{2} \mathrm{SO}_{4}$, and $\mathrm{NH}_{4} \mathrm{OH}$ before carrying out a heat treatment is a very potent way of removing a high amount of metallic impurities, thereby producing white-colored silica in high amounts. The results of our study confirm the findings from previous studies, as we could observe the grey color in all the untreated samples, irrespective of the amount of temperature applied (Fig. 1c). However, the treatment of barley grass waste with $2 \mathrm{M} \mathrm{HCl}$, followed closely by heat treatment, was found to give a whiter product (Fig. 1d). Apparently our XRF results showed higher amounts of $\mathrm{SiO}_{2}$ particles for nano silica synthesized at $600^{\circ} \mathrm{C}$ and $700^{\circ} \mathrm{C}$, respectively. This indicated that

Table 1. XRF results of nano silica.

\begin{tabular}{|c|c|c|c|c|}
\hline Oxides & Sample $1\left(400^{\circ} \mathrm{C}\right)$ & Sample $2\left(500^{\circ} \mathrm{C}\right)$ & Sample 3 $\left(600^{\circ} \mathrm{C}\right)$ & Sample $4\left(700^{\circ} \mathrm{C}\right)$ \\
\hline $\mathrm{SiO}_{2}$ & $93.0 \%$ & $93.5 \%$ & $93.5 \%$ & $94.1 \%$ \\
\hline $\mathrm{CaO}$ & 1 & 0.9 & 0.9 & 0.7 \\
\hline $\mathrm{MgO}$ & 0.9 & 0.8 & 0.8 & 0.8 \\
\hline $\mathrm{K}_{2} \mathrm{O}$ & 2.1 & 2.0 & 2.0 & 0.3 \\
\hline $\mathrm{Fe}_{2} \mathrm{O}_{3}$ & 0.5 & 0.3 & 0.3 & 0.6 \\
\hline $\mathrm{P}_{2} \mathrm{O}_{5}$ & 0.6 & 0.6 & 0.6 & 0.7 \\
\hline $\mathrm{Al}_{2} \mathrm{O}_{3}$ & 0.7 & 0.7 & 0.7 & 0.9 \\
\hline $\mathrm{B}_{2} \mathrm{O}_{3}$ & 1.2 & 1.2 & 1.2 & 0.9 \\
\hline
\end{tabular}


after acid treatments, a reasonable amount of heat is required to further remove the presence of impurities and increase the amount of pure silica obtained [27].

In the XRF results shown in Table 1, we observed that the amount of silicon oxide present in the samples was lower at $400^{\circ} \mathrm{C}$ with a rate percentage of $93 \%$ and was higher at $700^{\circ} \mathrm{C}$ with a $1.1 \%$ increase. Aluminum oxide is seen to have a steady percentage composition throughout all the temperature ranges. The results from the XRF were clearly in line with results from studies by Hui et al. and Seyed et al., respectively [23, 28]. Manganese, potassium, and phosphorus can be seen as some of the major impurities in the treated nano silica powder. Apparently, the high amounts of these compounds can be observed to have resulted from the use of fertilizers and soil nutrients in agricultural activities. The source of manganese and phosphorus can also be likened to originate from the basal media. Phosphate is a nutrient that is very important for many microorganisms such as fungi [29]. Many lignocellulosic fungi are known for degrading lignin through a method that produces an enzyme known as manganese peroxidase that could depolymerize lignin as well as convert it into products that are watersoluble in nature. Apparently, the acid treatment in the experimental procedure was necessary for removing metallic impurities from the barley grass waste [27].

a)

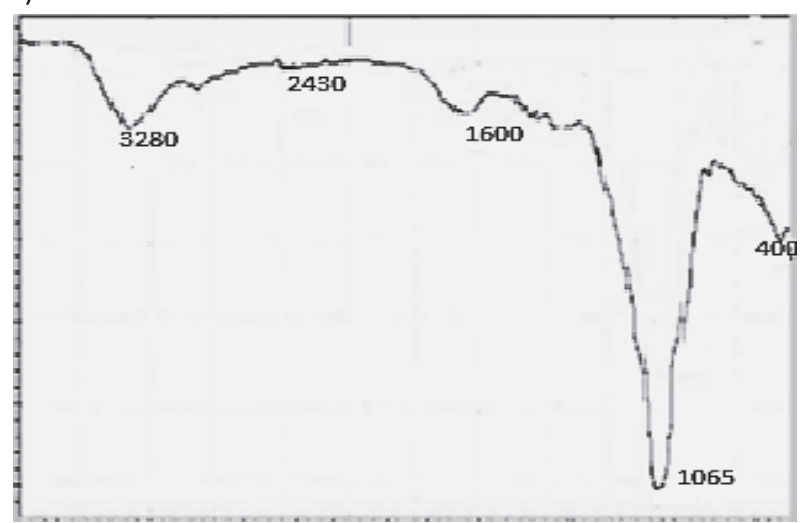

b)

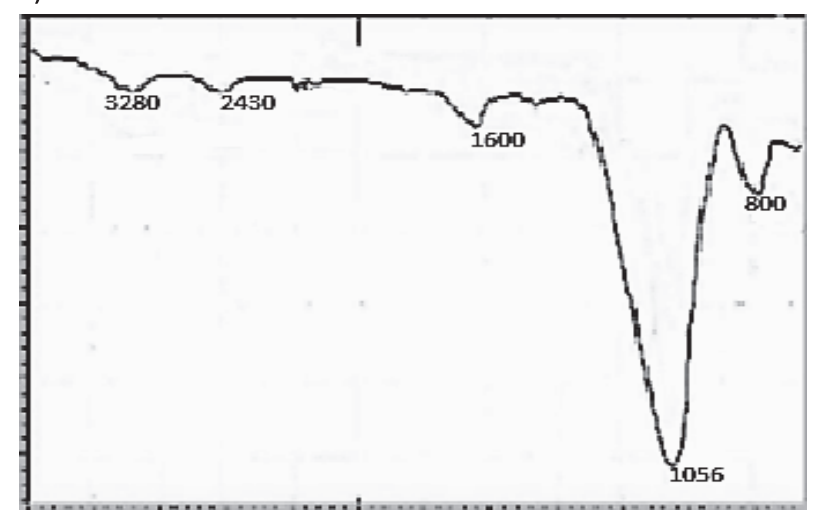

Fig. 2. FTIR results of synthesized nano silica obtained from acid-treated barley: a) raw barley without acid treatment and b) acid-treated barley followed by combustion.
FTIR Spectra of silica nanoparticle after calcinations at $700^{\circ} \mathrm{C}$ temperature is shown in Fig. 2. The dominant peak at $1065 \mathrm{~cm}^{-1}$ is attributed to vibrations that correspond with the asymmetric stretching vibrations of silicon bond ( $\mathrm{Si}-\mathrm{O}-\mathrm{Si}$ ), whereas the peak around $3280 \mathrm{~cm}^{-1}$ arises because of $\mathrm{OH}$ bending vibrations. At $1600 \mathrm{~cm}^{-1}$, untreated barley also showed absorbed water [23]. A comparison of the spectrum between treated and untreated barley is identified around the peak at $3280 \mathrm{~cm}^{-1}$, which is due to absorbed water. We also observed an insignificant peak in the vibrations of heat treated barley, and the peak at $400 \mathrm{~cm}^{-1}$ for non-heat-treated barley shifted to a higher wavelength of $800 \mathrm{~cm}^{-1}$, indicating the siloxane bond (Si-O-Si) was forming silicon from silica. Apparently, 1056,1000 , and $800 \mathrm{~cm}^{-1}$ peaks are attributed to the Si- OH, Si- O- Si asymmetric and symmetric stretching, respectively. Previous research revealed that barley extract gives a band between $4000-400 \mathrm{~cm}^{-1}$, in $(\mathrm{SiOH})$ group, indicating that these peaks are the main indices of the silica materials, which represent the successful production of silica nanoparticles [30, 31].

The SEM images are shown in Fig. 3. We notice that the structures are aggregated mostly in images $\mathrm{A}, \mathrm{B}$, and $\mathrm{C}$, these are for $400^{\circ} \mathrm{C}, 500^{\circ} \mathrm{C}$, and $600^{\circ} \mathrm{C}$, respectively. As the temperature increased the aggregation of the structures are reduced, as seen in Figure d) for $700^{\circ} \mathrm{C}$. In Figure b) we notice a decreased amount of aggregation. These aggregated structures are spherical in nature, and they began to aggregate less as the temperature approached $700^{\circ} \mathrm{C}$. Also, the SEM image at the same temperature showed the presence of well-defined circular shapes with less aggregation. Our study showed that with increasing temperature, a reduction in agglomeration occurs. In studies by Hui et al. [28] and Zaky et al. [21], porous aggregated structures were found around some of the particles, and as the temperature increased the aggregations that are
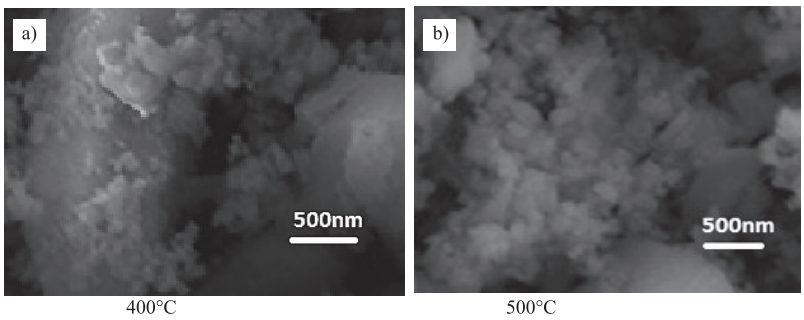

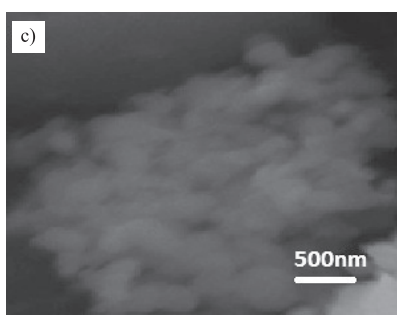

$600^{\circ} \mathrm{C}$

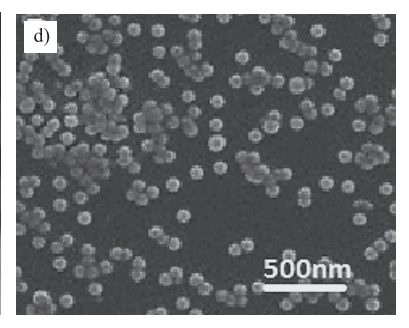

$700{ }^{\circ} \mathrm{C}$

Fig. 3. SEM images of nano silica final products synthesized at a) $400^{\circ} \mathrm{C}$, b) $500^{\circ} \mathrm{C}$, c) $600^{\circ} \mathrm{C}$, and d) $700^{\circ} \mathrm{C}$. 
Table 2. BET results for synthesized nano silica

\begin{tabular}{|c|c|c|}
\hline Diameter $(\mathrm{nm})$ & $\begin{array}{c}\text { Surface volume ratio } \\
\left(\mathrm{m}^{2} / \mathrm{g}\right)\end{array}$ & $\begin{array}{c}\text { Density } \\
\left(\mathrm{g} / \mathrm{cm}^{3}\right)\end{array}$ \\
\hline $150 \mathrm{~nm}$ & 323 & $<0.10$ \\
\hline
\end{tabular}

seen in the image decreased, which is also consistent with our results.

The size of nano particles were around $150 \mathrm{~nm}$ according to the BET result as shown in Table 2. The surface area for $700^{\circ} \mathrm{C}$ acid-treated barley revealed that $\mathrm{S}_{\mathrm{BET}}$ was $323 \mathrm{~m}^{2} \cdot \mathrm{g}^{-1}$. According to Sadek et al. [31], surface area and density are the two most prominent physical properties that can have effects on the quality as well as utility of chemicals in solid phase (this includes additives and pharmaceutical active ingredients) [31]. Contrasts in the surface area and porosity of particles inside the material, which generally may have the same physical measurements, can enormously impact its execution characteristics. As reported by Lazaro et al. [32], a high surface-area material equates to high surface energy. Subsequently, such materials are thermodynamically unstable. Various applications require nanosilica with specific surface area and pore sizes and volumes. Creating nanosilica that are suited to each application respectively is key to avoid shrinkage (in relation to pore volume) as well as the degree of aggregation.

The XRD patterns of nano silica powder obtained at the various temperatures gave sharp peak at $2 \theta=23^{\circ} \mathrm{C}$, indicating that there is little to no crystalline structure and that a high percentage of the particles are amorphous. The acid treatment of the barley grass at temperatures ranging between $600-700^{\circ} \mathrm{C}$ resulted in the formation of pure silica.

The EDX result shown in Fig. 5 coincides with the stoichiometry of the results from Fig. 1 at $700^{\circ} \mathrm{C}$, which

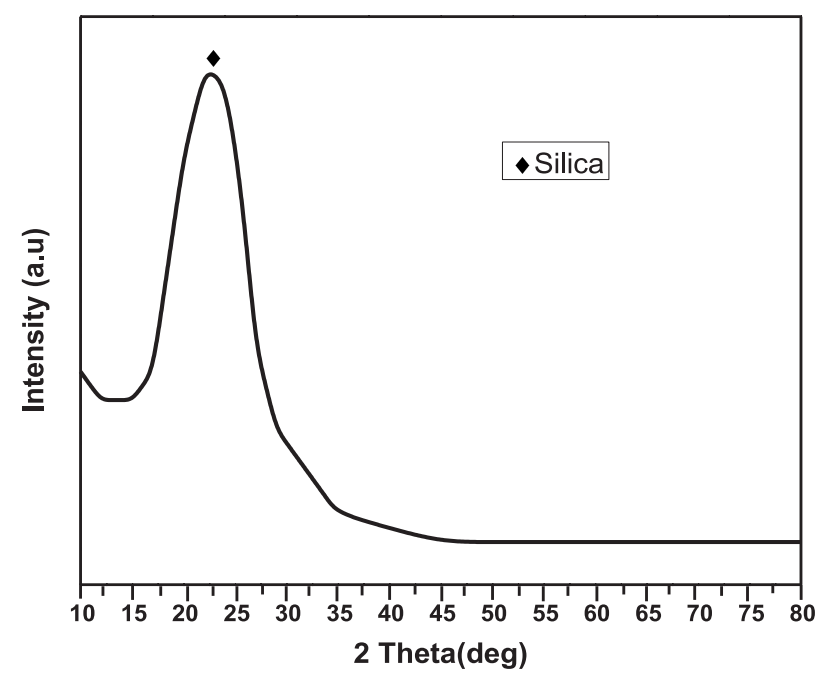

Fig. 4. XRD results of extracted silica from treated barley grass in acid, followed by combustion.

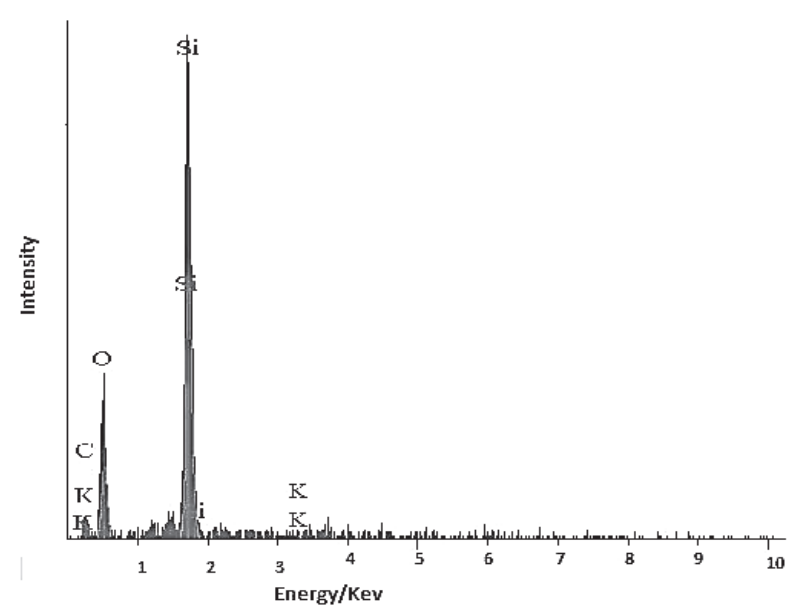

Fig. 5. EDX result analysis pattern of obtained nanosilica from treated barley.

shows that the silicon exists in oxide form: silicon and oxygen have the highest peaks compared to the results from research done by Singh et al [29] and Sadek et al. [31], nano silica synthesized from rice husk were shown to have silicon peaks at $2 \mathrm{KeV}$. The presence of silica is confirmed by the elemental analysis data graphs.

Differential scanning calorimetry as well as the thermographic analyzer techniques have been widely employed in the observation and investigation of
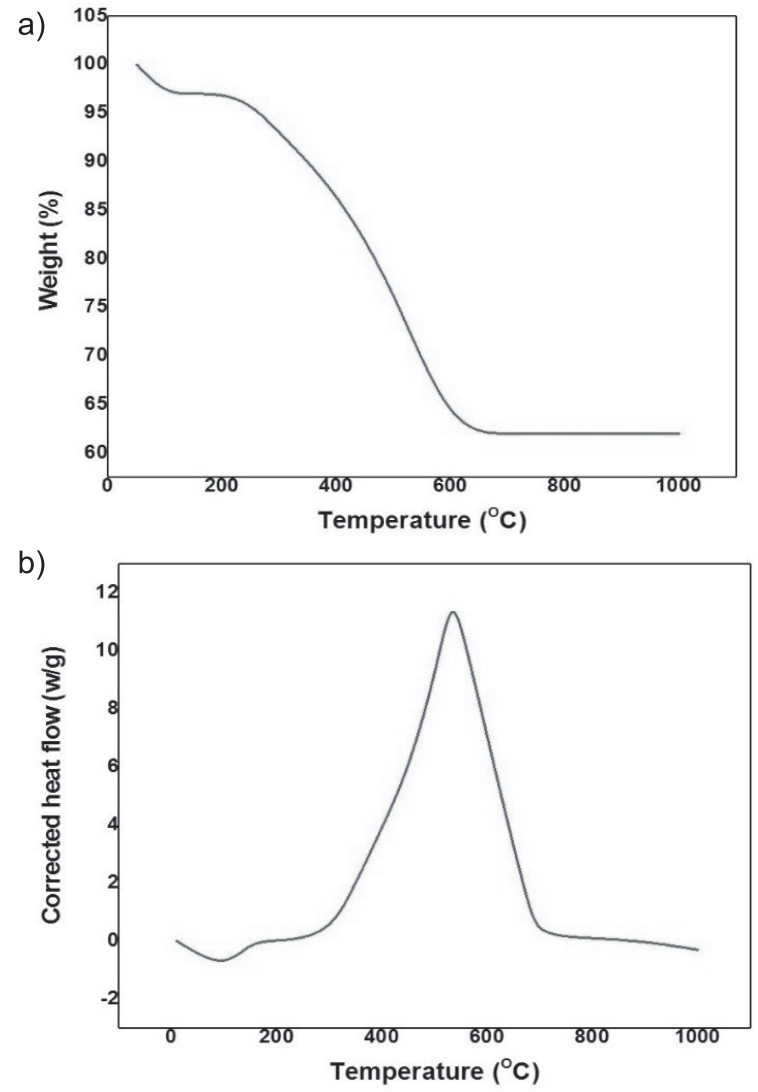

Fig. 6. TGA a) and DSC b) curve patterns of obtained nanosilica from treated barley. 
various phenomena that occur during thermal procedures. The DSC and TGA results for nano silica particles are shown in Fig. 6. There is an exothermal peak at $580^{\circ} \mathrm{C}$ in the DSC curve, and the TGA curve shows a high weight loss of more than $5 \%$ from $80^{\circ} \mathrm{C}$ to $200^{\circ} \mathrm{C}$. This arises because of humidity liberation, and about $30 \%$ at $200-600^{\circ} \mathrm{C}$ due to the loss of organic material, leaving the remaining $65 \%$ to correspond to $\mathrm{SiO}_{2}$ composite.

The mechanical properties of nano materials is important in showing how well the nano materials

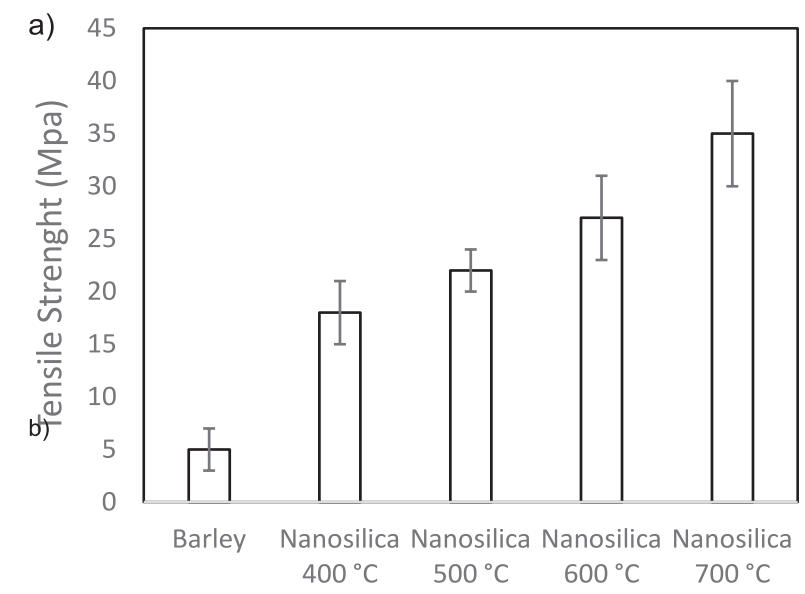

b)

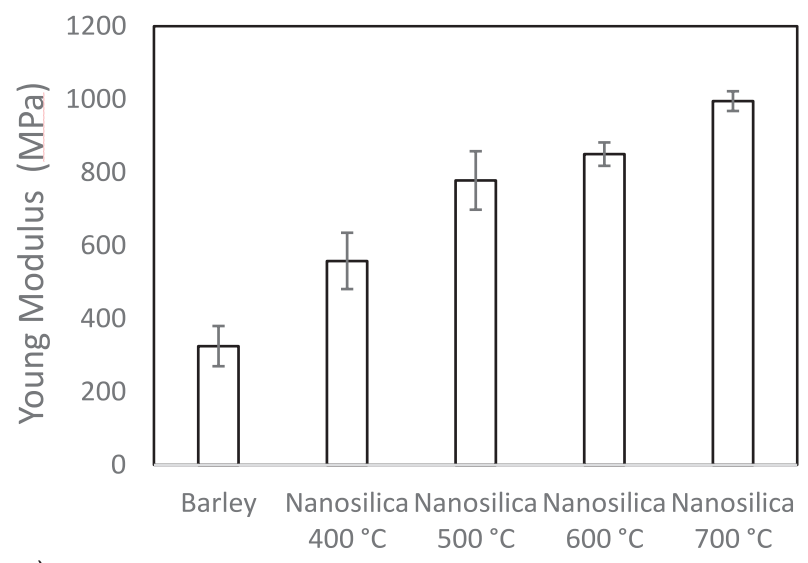

c)

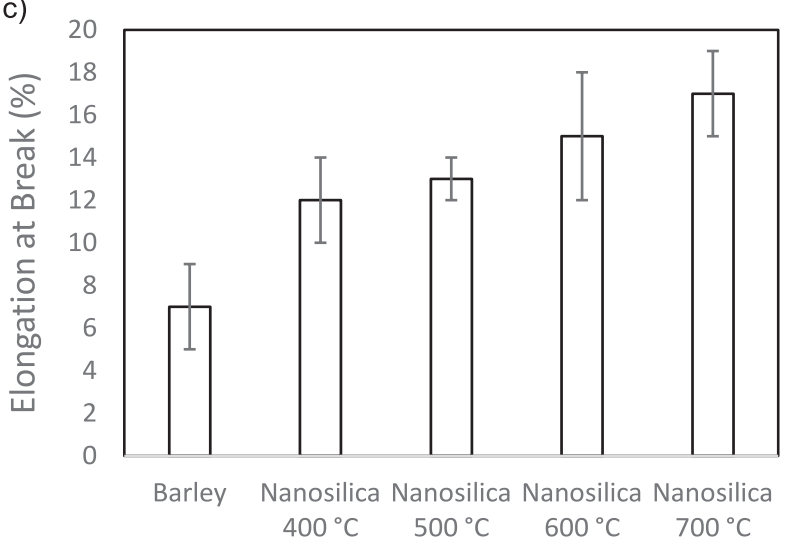

Fig. 7. a) Tensile strength results for nano silica at $400^{\circ} \mathrm{C}, 500^{\circ} \mathrm{C}$, $600^{\circ} \mathrm{C}$, and $700^{\circ} \mathrm{C}$; b) young modulus result for nano silica at $400^{\circ} \mathrm{C}, 500^{\circ} \mathrm{C}, 600^{\circ} \mathrm{C}$, and $700^{\circ} \mathrm{C}$; and c) elongation break result of nano silica at $400^{\circ} \mathrm{C}, 500^{\circ} \mathrm{C}, 600^{\circ} \mathrm{C}$, and $700^{\circ} \mathrm{C}$. would perform when used as adsorbent, which tells the amount of load the nano materials can withstand before stretching or breaking. The tensile strength of a material is the maximum stress that can be applied to it before it breaks. As observed in Fig. 7, the tensile strength of the material increases as the temperature increases, which indicates that the nanosilica synthesized at $700^{\circ} \mathrm{C}$ shows better mechanical properties with regards to tensile strength and would withstand more load. However, the difference in tensile strength at $400^{\circ} \mathrm{C}$ and $500^{\circ} \mathrm{C}$ was just $4 \mathrm{MPa}$, while $600^{\circ} \mathrm{C}$ and $700^{\circ} \mathrm{C}$ was $8 \mathrm{MPa}$. Our results indicate that nanosilica synthesized at $700^{\circ} \mathrm{C}$ showed better mechanical properties and optical stability. The tensile test gives information on the strength of materials under tensile forces. The tensile strength of a material is basically its ability to withstand tensile burdens without failing. Ductility measures a material's ability to elongate/stretch under tensile burdens. This is an imperative factor in metal framing forms since brittle metals will probably deform and break. Materials that deform under stress are unable to withstand high reusability procedures.

The results for young modulus as given in Fig. 7b) above shows that as temperature increases the young modulus increases, with the highest young modulus value of $995 \mathrm{MPa}$ at $700^{\circ} \mathrm{C}$. This clearly indicates that the temperature increase stabilizes the mechanical form of the material, and as such our nano particles will not be easily deformed irrespective of the amount of load. According to studies conducted by Pham et al. [33], we can attribute the increase in the young modulus and tensile strength of nano silica at $700^{\circ} \mathrm{C}$, which can be associated with the filling effect of the fine particles of the nano silica, which as observed in our characteristics showed that the particles are well shaped and smoother at $700^{\circ} \mathrm{C}$ [33].

The elongation break results for synthesized nano silica as shown in Fig. 7c) shows that the percentage of elongation increases with the temperature increase, which means that there is a lower tendency for the integrity of the material to be tempered at the highest temperature, which in this case happens to be at $700^{\circ} \mathrm{C}$. This indicates that nano silica synthesized at $700^{\circ} \mathrm{C}$ showed better mechanical properties and stability.

\section{Conclusion and Sustainable Path Forward}

The investigation presented here provides an environmentally friendly methodology of converting barley grass waste in silica nanoparticles. In addition to methodology, the study also shows how these nanomaterials may be used for applications that can lead to lightweight and stronger materials based on nano silica. In this study, nano silica synthesis was conducted at four different temperatures $\left(400^{\circ} \mathrm{C}, 500^{\circ} \mathrm{C}\right.$, $600^{\circ} \mathrm{C}$, and $700^{\circ} \mathrm{C}$ ), and we observed their mechanical properties. The results showed the best mechanical properties at $700^{\circ} \mathrm{C}$. The increasing use of silica nanoparticles (SNPs) in various industrial products along 
with its high absorption capacity makes the production of silica from waste products a viable undertaking. Barley grass further undergoes some treatment process for removal of metallic impurities, which further effects its quality and integrity when used as a precursor for the synthesis of nano silica. The acid treatment and combustion method were used for the synthesis of silica nano particles from barley. The synthesis of nano silica from barley in this study has provided solutions to two major problems: the production of useful nanoparticles from agricultural waste and the sustainable use of environmental waste. The resulting nano silica particles are promising material that can be used as adsorbents in the cleanup of wastewater or water having other forms of contaminants, in addition to its useful mechanical properties.

\section{Conflict of Interest}

All authors declare no conflict of interest.

\section{References}

1. ANUPAMA A.K., KUMAR P., G.D. RANSINCHUNG R.N., Use of Various Agricultural and Industrial Waste Materials in Road Construction, Procedia - Social and Behavioral Sciences, 104, 264, 2013.

2. KARABÍN M., JELÍNEK L., KOTRBA P., CEJNAR R., DOSTÁLEK P., Enhancing the performance of brewing yeasts. Biotechnology Advances. (https://doi.org/10.1016/j. biotechadv.2017.12.014) 2018

3. VAN DONKELAAR L.H.G., NOORDMAN T.R., BOOM R.M., VAN DER GOOT A.J. Pearling barley to alter the composition of the raw material before brewing, Journal of Food Engineering, 150, 44, 2015.

4. FILLAUDEAU L., BLANPAIN-AVET P., DAUFIN G., Water, wastewater and waste management in brewing industries. Journal of Cleaner Production, 14 (5), 463. 2006.

5. AYUB S., ALI S.I., KHAN N.A., RAO R.A.K., Treatment of wastewater by agricultural waste, Environ. Prot. Control J., 2 (1), 5, 1998.

6. SRINIVASAN K., BALASUBRAMANIAM N., RAMAKRISHNA T.V., Studies on chromium removal by rice husk carbon, Indian J. Environ. Health, 30 (4), 376, 1988.

7. TAN W.T., OOI S.T., LEE C.K., Removal of chromium (VI) from solution by coconut husk and palm pressed fibre, Environ. Technol., 14 (3), 277, 1993.

8. KAVAZ D., ODABAS S., DENKBAS E.B., VASEASHTA A. A practical methodology for $\operatorname{IgG}$ purification via chitosan based magnetic nanoparticles, Digest Journal of Nanomaterials and Biostructures, 7 (3), 1165, 2012.

9. KAVAZ D., ÇIRAK T., BAYRAM C., ÖZTÜRK E., DENKBAŞ E.B., Preparation of Magnetic Chitosan Nanoparticles for diverse Biomedical Applications, Functionalized Nanoscale Materials, Devices And Systems, NATO Science for Peace and Security Series B Physics and Biophysics, 31, 2008.

10. DENKBAŞ E.B., BAYRAM C., KAVAZ D., ÇIRAK T., DEMIRBILEK M., Nanoplatforms for Detection,
Remediation and Protection Against Chem-Bio Warfare, in Technological Innovations in Sensing and Detection of Chemical, Biological, Radiological, Nuclear Threats and Ecological Terrorism, Ed. Ashok Vaseashta, Eric Braman, and Philip Susmann, Springer, NY, 191, 2012.

11. STANDER L., THEODORE L. Environmental Implications of Nanotechnology - an Update, International Journal of Environmental Research and Public Health, 8 (2), 470, 2011.

12. VASEASHTA, ASHOK, Life Cycle Analysis of Nanoparticles, ISBN-13: 978-1605950235, Destech Publication, Lancaster, PA. 2015.

13. SALATA O.V. Applications of nanoparticles in biology and medicine, Journal of Nanobiotechnology, 2, 3, 2004.

14. KAVAZ D., AIGBE R., AUGUSTINE E.E. Detection of Pathogens in Aqueous Media with Modified Magnetic Nanoscaled Particles, Fresenius Environmental Bulletin, 26 (No. 1a/2017), 761, 2017.

15. SARAWADE P.B., KIM J.K, HILONGA A., KIM H.T. Preparation of hydrophobic mesoporous silica powder with a high specific surface area by surface modification of a wet-gel slurry and spray-drying. J. Power Tech., 197 (3), 288, 2010.

16. GHORBANI F., SANATI A.M., MALEKI M. Production of Silica Nanoparticles from Rice Husk as Agricultural Waste by Environmental Friendly Technique, Environmental Studies of Persian Gulf, 2 (1), 56, 2015.

17. WANG W., MARTIN J.C., FAN X., HAN A., LUO Z., SUN L., Silica Nanoparticles and Frameworks from Rice Husk Biomass, ACS Appl. Mater. Interfaces, 4 (2), 977, 2012.

18. SHARIFF I., SHAOBIN W., HA M.A. Removal of emulsified oil from oily wastewater using agricultural waste barley straw, Biochemical Engineering Journal, 49 (1), 78, 2010.

19. JAFARI M., NOURI A., KAZEMIMOGHADAM M., MOHAMMADI T. Investigations on hydrothermal synthesis parameters in preparation of nanoparticles of LTA zeolite with the aid of TMAOH, Powder Technology, 237, 442, 2013

20. HENCH L.L., WEST J.K. The Sol-Gel process, Chemical Reviews, 90 (1), 33, 1990.

21. ZAKY R., HESSIEN M., EL-MIDANY A.A., KHEDR M.H., ABDEL-AAL E.A., EL BARAWY K.A. Preparation of silica nanoparticles from semi burned rice straw ash. Powder Technol., 185 (1), 31, 2008.

22. ESPÍNDOLA-GONZALEZ A., FUENTES-RAMIREZ R., MARTÍNEZ-HERNÁNDEZ A.L., CASTAÑO V.M., VELASCO-SANTOS C. Structural Characterization of Silica Particles Extracted from Grass Stenotaphrum secundatum: Biotransformation via Annelids, Advances in Materials Science and Engineering, Volume 2014, Article ID 956945, 7, 2014.

23. SEYED N.A., AHMAD R.D., AMIR J. Synthesis and characterization of LTA nanozeolite using barley husk silica. Material research bulletin, 48 (5), 1753, 2013.

24. TZONG H.L., YANG C.C. Synthesis and surface characteristics of nanosilica produced from alkali extracted rice husk ash. Material science and engineering, 176 (7), 521, 2011.

25. BOGUSH G.H., TRACY M.A., ZUKOSKI C.F. Preparation of monodisperse silica particles: control of size and mass fraction, Journal of Non-Crystalline Solids, 104 (1), 95, 2013.

26. GHORBANI F., HABIBOLLAH Y., MEHRABAN Z., 
ÇELIK M.S., GHOREYSHI A.A., ANBIA M. Preparation and characterization of highly pure silica from sedge as agricultural waste and its utilization in the synthesis of mesoporous silica MCM-41. Journal of the Taiwan Institute of Chemical Engineers, 44 (5), 821, 2013.

27. MAHMUD A., MEGAT-YUSOFF P.S.M., AHMAD F., FAREZZUAN A.A. Acid leaching as efficient chemical treatment for rice husk in production of amorphous silica nanoparticles, ARPN Journal of Engineering and Applied Sciences, 11 (22), 13384, 2016.

28. HUI C., FEN W., CONGYUM Z., YUANCHANG S., GUIYUM J., SHILING Y. Preparation of nano silica materials, the concept from wheat straw, Journal of noncrystalline solids, $\mathbf{3 8 6}$ (50-51), 2781, 2010.

29. SINGH D., KUMAR R., KUMAR A., RAI K.N. Synthesis and characterization of rice husk silica, silica-carbon composite and $\mathrm{H}_{3} \mathrm{PO}_{4}$ activated silica, Ceramica, 54 (330), 203, 2008.
30. ATHINARAYANAN J., PERIASAMY V.S., ALHAZMI M., ALATIAH K.A., ALSHATWI A.A. Synthesis of biogenic silica nanoparticles from rice husks for biomedical applications, Ceramics International, 41, 275, 2015.

31. SADEK M.O., REDA M.S., AL-BILALI K.R. Preparation and Characterization of Silica and Clay-Silica CoreShell Nanoparticles Using Sol-Gel Method, Advances in Nanoparticles, 2 (2), 165, 2013.

32. LAZARO A., VAN DE GRIEND M.C., BROUWERS H.J.H., GEUS J.W. The influence of process conditions and Ostwald ripening on the specific surface area of olivine nano-silica. Microporous and Mesoporous Materials, 181, 254, 2013.

33. PHAM T.D., VU C.M., CHOI H.J. Enhanced Fracture Toughness and Mechanical Properties of Epoxy Resin with Rice Husk-based Nano-Silica, Polymer Science, Series A, 59 (3), 437, 2017. 
